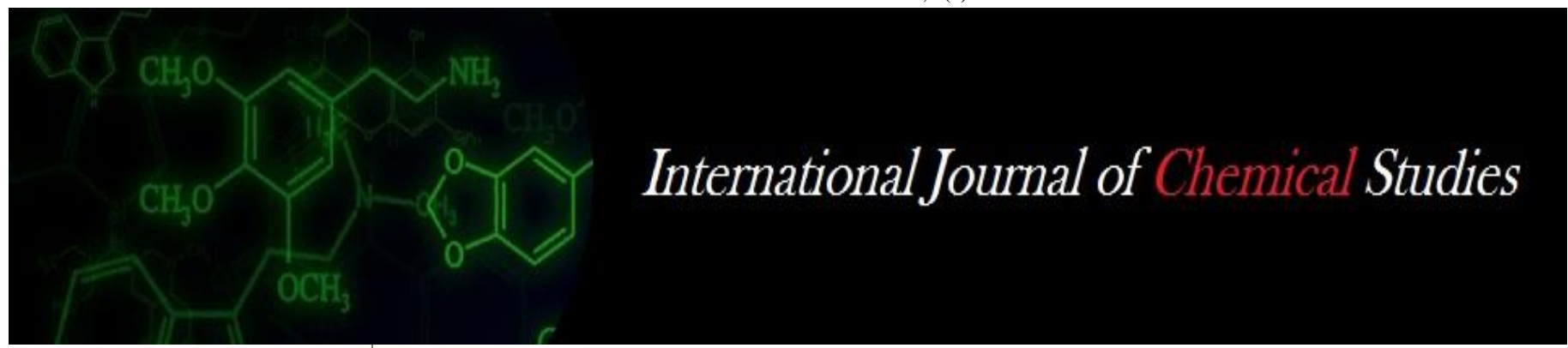

P-ISSN: 2349-8528

E-ISSN: 2321-4902

www.chemijournal.com

IJCS 2020; 8(2): 176-179

(C) 2020 IJCS

Received: 04-01-2020

Accepted: 06-02-2020

\section{Ranjit Saroj}

G. B. Pant University of

Agriculture and Technology,

Pantnagar, Uttarakhand, India

Surendra Singh

G. B. Pant University of

Agriculture and Technology,

Pantnagar, Uttarakhand, India

Nidhi Bhatt

G. B. Pant University of

Agriculture and Technology,

Pantnagar, Uttarakhand, India

Corresponding Author:

Ranjit Saroj

G. B. Pant University of

Agriculture and Technology,

Pantnagar, Uttarakhand, India

\section{Studies of genetic diversity analysis in rice (Oryza sativa $L$.$) genotypes for yield and yield$ contributing characters}

\author{
Ranjit Saroj, Surendra Singh and Nidhi Bhatt
}

DOI: https://doi.org/10.22271/chemi.2020.v8.i2c.8763

\begin{abstract}
Rice (Oryza sativa L.), an autogamous crop, is the staple food of most of the people of South-Eastern Asia. Around $90 \%$ of all rice grown in the world is produced and consumed in the Asian region specifically China followed by India. Hundred genotypes (indigenous collection) from NBPGR with four checks were evaluated at N. E. Borlaug Crop Research Centre of G.B. Pant University of Agriculture and Technology, Pantnagar, Uttarakhand, India, during kharif season, 2015-17. Analysis of variance indicated adequate genetic variability among the experimental materials. Based on Hierarchical cluster analysis, the 104 genotypes including check were grouped into 8 clusters. The maximum numbers of genotypes (44) were grouped in Cluster III and minimum (1) in Clusters I and VIII. The maximum divergence was observed between Clusters I and VII (415.80) and least divergence was observed between Clusters IV and V (90.23). Cluster I have most desirable genotypes as it exhibited highest cluster mean values for majority of the characters under study. Based on inter-cluster distance, cluster mean values and per se performance, the potential parental combinations that could be considered for enhancing the overall yield levels in rice were, IC75747, IC75738, IC75843, IC75968, IC75828, IC75811, IC75839, IC458780.
\end{abstract}

Keywords: Genetic diversity, rice, cluster analysis

\section{Introduction}

Rice (Oryza sativa L.) is a cleistogamous, $\mathrm{C}_{3}$ and self-pollinated crop. It belongs to Oryza Genus (22 wild species and 2 cultivated species) and Poaceae family. Rice is the most essential food of more than $60 \%$ of the world's population. It is expected to world population reach eight billion by 2030 and rice production must increase by 50 per cent to meet the growing demand (Khush and Brar 2002) ${ }^{[9]}$. It is mainly used as a major source of human food besides animal feed, production of alcoholic beverages like wine, rice bran oil, fuel and manufacture of insulation materials (Chakravarthi and Naravaneni, 2006). Yield is the complex trait which is associated with different yield contributing traits. Genetic diversity is an important tool for a crop improvement programme, as it helps in the development of superior recombinants (Manonmani and Khan, 2003) ${ }^{[11]}$. Genetic divergence among the genotypes plays an important role in selection of parents having wider variability for different traits (Nayak et al., 2004) ${ }^{[12]}$. Genetic diversity in crop plants is essential to withstand level of high productivity (Tripathi et al., 2013) ${ }^{[13]}$. The availability of morphogenetic variation in agronomic characters of a crop would be of considerable importance in determining the best method to improve the yield of that crop.

\section{Material and methods}

A total of hundred rice germplasm line and four checks Jaya, Swarna, Pusa Basmati 1 and IR 64 consisted of experiment materials for the investigation (Table 1). The genotypes were evaluated in augmented design -II (Federer, 1956 \& 1977). Hundred test entries were planted once without replication in five blocks, each block had twenty test entries and the five checks were randomized within the block and replicated across the five blocks. Each plot consists of 2 rows of $2 \mathrm{~m}$ length (plot size $0.8 \mathrm{~m}^{2}$ ) with between rows and within rows spacing of $20 \mathrm{~cm}$ and $15 \mathrm{~cm}$, respectively. 
The observations were recorded on 15 morphological characters Days to $50 \%$ flowering, Plant height $(\mathrm{cm})$, Tiller number per plant, Panicle length $(\mathrm{cm})$, Number of grains per panicle, Filled grains per panicle, Unfilled grains per panicle, 1000 grain weight $(\mathrm{g})$, Grain weight per panicle $(\mathrm{g})$, Grain yield per plant $(\mathrm{g})$, Grain yield per plot $(\mathrm{g})$, Grain yield per ha (q), Kernel length (mm), Kernel breadth ( $\mathrm{mm})$, LB ratio on plot basis as well as based on five randomly chosen competitive plants from each plot.

\section{Statistical analysis}

The genetic divergence was estimated using the Hierarchical cluster analysis which was performed on the basis of Euclidean distance between the genotypes. The Euclidean distance between $\mathrm{i}^{\text {th }}$ and $\mathrm{k}^{\text {th }}$ accession was calculated by $D_{i k}=\left[E_{j=1}^{n}\left(A_{i j}-A_{k j}\right)^{2}\right]^{1 / 2}$

Where, $D_{i k}$ is Euclidean distance between $i^{\text {th }}$ and $\mathrm{k}^{\text {th }}$ accession, $\mathrm{A}_{\mathrm{ij}}$ is performance of $\mathrm{i}^{\text {th }}$ accession for $\mathrm{j}^{\text {th }}$ character, $A_{\mathrm{kj}}$ is performance of $\mathrm{k}^{\text {th }}$ accession for $\mathrm{j}^{\text {th }}$ character, $\mathrm{m}$ is number of accessions ( $\mathrm{I}$ or $\mathrm{k}=1,2 \ldots \mathrm{m}$ ), $n$ is number of characters $(j=1,2 \ldots n)$.

Table 1: List of the rice genotypes/codes

\begin{tabular}{|c|c|c|c|c|c|c|c|c|c|c|c|c|c|}
\hline $\begin{array}{c}\text { S. } \\
\text { No. }\end{array}$ & $\begin{array}{c}\text { Genotypes } \\
\text { identity code } \\
\text { No. (IC No.) }\end{array}$ & $\begin{array}{l}\text { S. } \\
\text { No }\end{array}$ & $\begin{array}{c}\text { Genotypes } \\
\text { identity code } \\
\text { No. (IC No.) } \\
\end{array}$ & $\begin{array}{c}\text { S. } \\
\text { No. }\end{array}$ & $\begin{array}{c}\text { Genotypes } \\
\text { identity Code } \\
\text { No. (IC No.) } \\
\end{array}$ & $\begin{array}{l}\text { S. } \\
\text { No }\end{array}$ & $\begin{array}{c}\text { Genotypes } \\
\text { identity code } \\
\text { No. (IC No.) } \\
\end{array}$ & $\begin{array}{l}\text { S. } \\
\text { No. }\end{array}$ & $\begin{array}{c}\text { Genotypes } \\
\text { identity Code } \\
\text { No. (IC No.) } \\
\end{array}$ & $\begin{array}{l}\text { S. } \\
\text { No }\end{array}$ & $\begin{array}{c}\text { Genotypes } \\
\text { identity code } \\
\text { No. (IC No.) } \\
\end{array}$ & $\begin{array}{c}\text { S. } \\
\text { No. }\end{array}$ & $\begin{array}{c}\text { Genotypes } \\
\text { identity Code } \\
\text { No. (IC No.) }\end{array}$ \\
\hline 1 & $459770 \mathrm{X}$ & 16 & 75741 & 31 & 75771 & 46 & 75829 & 61 & 75844 & 76 & 75861 & 92 & 75982 \\
\hline 2 & 458768 & 17 & 75747 & 32 & 75773 & 47 & 75846 & 62 & 75864 & 77 & 75891 & 93 & 75957 \\
\hline 3 & 454588 & 18 & 75737 & 33 & 75783 & 48 & 75819 & 63 & 75865 & 78 & 75894 & 94 & 75969 \\
\hline 4 & $449549 X$ & 19 & 75756 & 34 & 755785 & 49 & 75830 & 64 & 75872 & 79 & 75896 & 95 & 75970 \\
\hline 5 & $449560 X$ & 20 & 75782 & 35 & 75790 & 50 & 75843 & 65 & 7574 & 80 & 75889 & 96 & 75955 \\
\hline 6 & 454612 & 21 & 75799 & 36 & 75793 & 51 & 75845 & 66 & 75879 & 81 & 75913 & 97 & 75958 \\
\hline 7 & 458780 & 22 & 75789 & 37 & 75795 & 52 & 75847 & 67 & 75882 & 82 & 75919 & 98 & 75960 \\
\hline 8 & 75735 & 23 & 75791 & 38 & 75797 & 53 & 75839 & 68 & 75877 & 83 & 75920 & 99 & 75965 \\
\hline 9 & 75748 & 24 & 75800 & 39 & 75798 & 54 & 75822 & 69 & 75855 & 84 & 75927 & 100 & 75966 \\
\hline \begin{tabular}{|l|}
10 \\
\end{tabular} & 75754 & 25 & 75801 & 40 & 75803 & 55 & 7525 & 70 & 75856 & 85 & 75930 & & \\
\hline 11 & 75757 & 26 & 75802 & 41 & 75804 & 56 & 75832 & 71 & 75857 & 86 & 75956 & & \\
\hline \begin{tabular}{|l|l|}
12 \\
\end{tabular} & 75761 & 27 & 75767 & 42 & 75786 & 57 & 75811 & 72 & 75859 & 87 & 75968 & & \\
\hline 13 & 75732 & 28 & 75768 & 43 & 75772 & 58 & 75821 & 73 & 75860 & 88 & 75972 & & \\
\hline 14 & 75731 & 29 & 75769 & 44 & 75775 & 59 & 75828 & 74 & 75849 & 89 & 75961 & & \\
\hline 15 & 75738 & 30 & 75770 & 45 & 75779 & 60 & 75834 & 75 & 75851 & 90 & 75963 & & \\
\hline
\end{tabular}

Results and Discussion

Estimation of Genetic Divergence through Hierarchical Cluster Analysis (HCA)

The adjusted mean of genotypes were subjected to Hierarchical Cluster Analysis (HCA) and the genotypes were grouped based on $40 \%$ dissimilarity level and same study by (Ward Jr, J. H. (1963) ${ }^{[14]}$. Hundred test genotypes and four checks were grouped in 8 clusters based on hierarchical cluster analysis. Cluster III had the highest number of genotypes (44) followed by Cluster V with 37 accessions, Cluster VII with 8 accessions, cluster II with 6 accessions, cluster VI with 2 accessions, cluster I and VIII with only1 accessions per genotype.

\section{Inter and intra-cluster distance}

Highest intra-cluster distance was recorded for cluster III (72.11) followed by cluster VII (58.32) and lowest for cluster I and cluster VIII (0.0). The inter-cluster distance was highest between cluster I and cluster VII (416.80) followed by cluster I and cluster VIII (395.78) on the other hand lowest intercluster distance was estimated between cluster IV and cluster V (90.23) (Table 2). Highest inter-cluster distance between cluster I and cluster VII revealed that these two clusters and genotypes of these clusters are distinctly related to each other. Diverse clusters would generate a high variability to scope for effective selection in the segregating generations for the development of high yielding rice cultivars. For grain yield per ha, the accessions IC75747, IC75738, IC75843, IC75968, IC75828, IC75811, and IC75839 have been identified as promising donors. One Accession IC75828 was identified to be promising donor for characters number of grains per panicle, grain yield per plant, grain yield per plot, grain yield per ha. These yield contributing characters possessing accessions can be used as donors in yield improvement. Donors for earliness in flowering were identified, IC454588, IC458768, IC75821 and IC459770X.Whereas accessions IC75839, IC75737, IC75843, IC75856 identified as donors for more tillers per plant (Table 3). Therefore these genotypes could be used to breed short duration and high yielding cultivars. Accessions IC458780, IC75828 had significantly higher grain yield per plant than best check (Jaya $51.76 \mathrm{~g}$ ). Accession IC458780 showed significant grain weight per panicle than best check [Jaya (2.34g)] accession IC449549X had significantly plant height, filled grains per panicle than best check Jaya. Accession IC449549X also had number of grains per panicle which is superior to Pusa Basmati 1. No accession showed more kernel length and LB ratio than check. There was more number of Accessions for more plant height and only one had dwarf plant height. The accession IC75799 had dwarf stature than superior check Swarna (Table 3).

Table 2: Intra (diagonal) and inter -cluster (Off-diagonal) distances based on Hierarchical Cluster Analysis of rice germplasm:

\begin{tabular}{|c|c|c|c|c|c|c|c|c|}
\hline Cluster & I & II & III & IV & V & VI & VII & VIII \\
\hline I & 0.0 & 128.16 & 234.00 & 306.30 & 335.83 & 367.12 & 416.80 & 395.78 \\
\hline II & & 55.37 & 147.08 & 224.77 & 249.98 & 302.08 & 333.20 & 306.55 \\
\hline III & & & 72.11 & 110.98 & 125.43 & 183.28 & 204.35 & 183.41 \\
\hline IV & & & & 30.75 & 90.23 & 137.37 & 145.87 & 101.53 \\
\hline V & & & & & 54.80 & 103.36 & 101.42 & 109.29 \\
\hline VI & & & & & & 17.27 & 100.27 & 151.41 \\
\hline VII & & & & & & & 58.32 & 107.22 \\
\hline VIII & & & & & & & & 0.0 \\
\hline
\end{tabular}




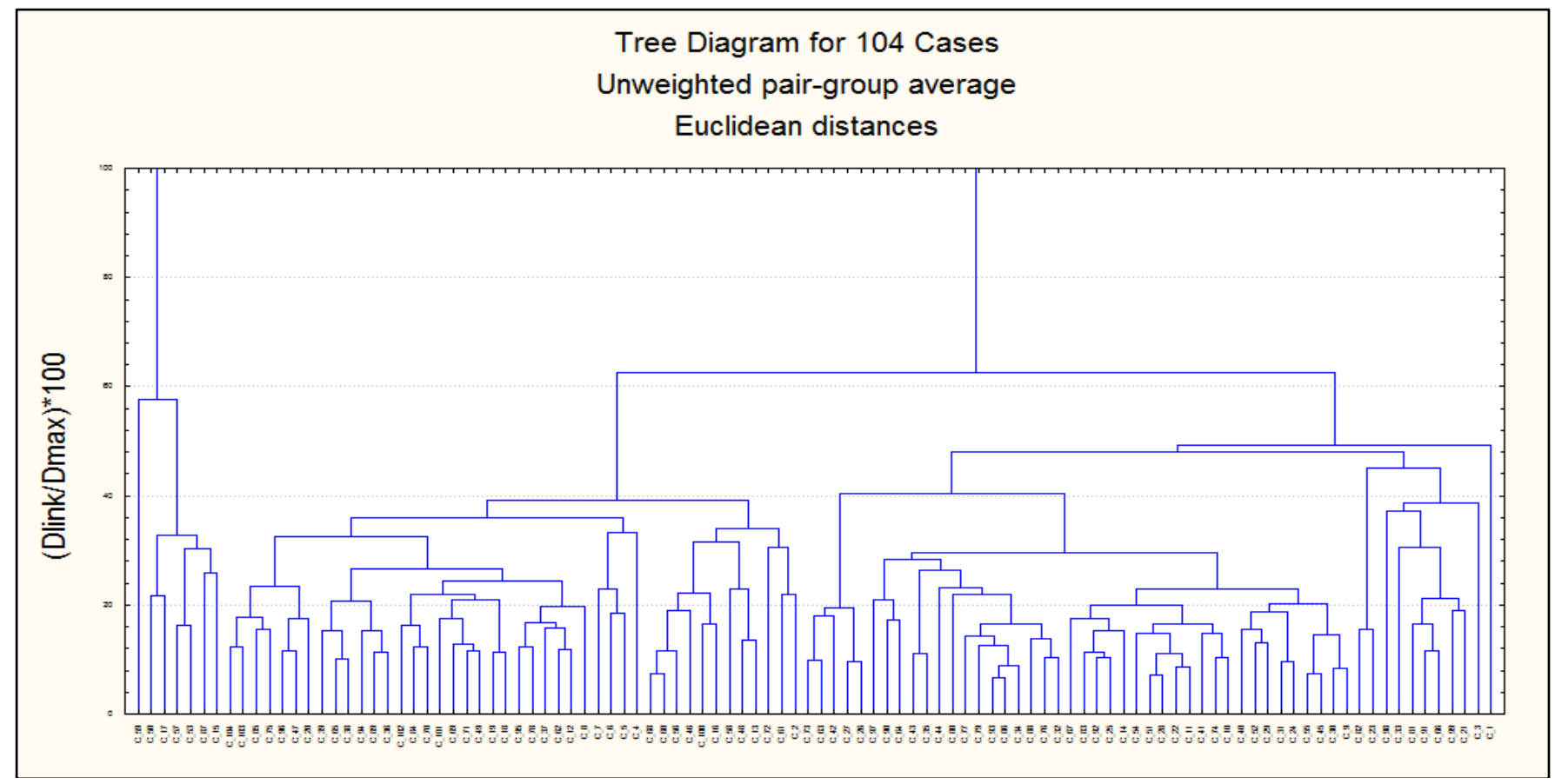

Fig 1: Clusters of 100 genotypes and 4 checks using Hierarchical cluster analysis method

\section{Conclusion}

In the context of all the above observations, it can be summarized that adequate amounts of genetic diversity for yield and its contributing characters existed among the experimental materials (100 genotypes +4 checks $)$ taken up for the present study. High inter-cluster distance between certain clusters obtained through genetic diversity analysis indicated that hybridization between superior genotypes obtained from these clusters would be highly promising to bring about yield improvement in rice.

Table 3: Potential donor identified for different characters

\begin{tabular}{|c|c|c|c|}
\hline S. No. & Characters & & Donor \\
\hline \multirow{2}{*}{1.} & \multirow{2}{*}{ Days to $50 \%$ flowering } & Early & IC454588, IC458768, IC75821, IC459770X, \\
\hline & & Late & IC75965, IC75790, IC75793, IC75798, IC75963, IC75961. \\
\hline \multirow{2}{*}{2.} & \multirow{2}{*}{ Plant height $(\mathrm{cm})$} & Dwarf & IC75799. \\
\hline & & Tall & IC454612, IC459770X, IC458780, IC449549X, IC75732. \\
\hline 3. & Tillers/plant & & IC75839, IC75737, IC75843, IC75856. \\
\hline 4. & Panicle length $(\mathrm{cm})$ & & IC75801, IC75800, IC75849, IC75894. \\
\hline 5. & Number of grains/ Panicle & & IC449549X, IC75865, IC75828, IC 75860, IC75889 \\
\hline 6. & Filled grains/panicle & & IC449549X. \\
\hline 7. & Unfilled grains/panicle & Low & IC454588, IC459770X, IC458768, IC75802. \\
\hline 8. & 1000 grain weight $(\mathrm{g})$ & & IC454612, IC75956. \\
\hline 9. & Kernel length (mm) & & \\
\hline \multirow{2}{*}{10 . } & \multirow{2}{*}{ Kernel breadth (mm) } & Low & IC75773, IC75829, IC75811. \\
\hline & & high & IC75958, IC75822, IC75978. \\
\hline 11. & $\mathrm{~L} B$ ratio & & IC75799, IC75847, IC75859, IC75851 \\
\hline 12. & Grain weight/ panicle $(\mathrm{g})$ & & IC458780. \\
\hline 13. & Grain yield/plant $(\mathrm{g})$ & & IC458780, IC75828. \\
\hline 14. & Grain yield/plot $(\mathrm{g})$ & & IC75747, IC75738, IC75843, IC75968, IC75828, IC75839. \\
\hline 15. & Grain yield/ha $(q)$ & & IC75747, IC75738, IC75843, IC75968, IC75828, IC75811, IC75839. \\
\hline
\end{tabular}

\section{Reference}

1. Ali SS, Jafri SJH, Khan MG, Butt MA. Heritability and genetic advance estimates for agronomic traits in rice. Pakistan Journal of Agriculture Agricultural-Engineering Veterinary Sciences. 1993; 9(1, 2):34-40.

2. Allard I. Principles of Plant Breeding, Chapter 6 through Chapter 9, University of California, Davis, 1960.

3. Bharadwaj CH, Tara SC, Subramanyam D. Evaluation of different classificatory analysis methods in some rice collection. Ind, J Agric. Sci. 2001; 71(2):123-125.

4. Bhati M, Babu GS, Rajput AS. Genetic variability, correlation and path coefficient for grain yield and quantitative traits of elite rice (Oryza sativa L.) genotypes at Uttar Pradesh. Electronic Journal of Plant Breeding. 2015; 6(2):586-591.

5. Burton GW. Quantitative inheritance in grasses. Proc. Sixth Grassland Congress. 1952; 1:277-283.

6. Chakravarthi, B. Kalyan, and Rambabu Naravaneni. SSR marker based DNA fingerprinting and diversity study in rice (Oryza sativa. L). African Journal of Biotechnology. 2006; 5.9.

7. Chowdhury RK, Singh RK. Rice seed supply in eastern India. In : Rainfed Rice - A Source Book of Best Practices and Strategies in Eastern India (Ed. Singh V. P. and Singh, R. K.), IRRI and Manila, Philippines, 2000, 292. 
8. Federer WT, Raghavarao D. On augmented designs. Biometrics, 1975, 29-35.

9. Johnson HW, Robinson HF, Comstock RE. Genotypic and phenotypic correlations and their implications in selection. Agron. J. 1955; 47:477-483.

10. Khush GS, Brar DS. Biotechnology for rice breeding: progress and impact. In: Sustainable rice production for food security. Proceedings of the 20th Session of the International Rice Commission. Bangkok, Thailand, 2002.

11. Lush JL. Heritability of quantitative characters of farm animals. Proc. 8th Int. Cong. of Genet. Suppl. Hereditis, 1949; I:356-375.

12. Manonmani S, Fazlullah Khan AK. Analysis of genetic diversity for selection of parents in rice. Oryza. 2003; 40:54-56.

13. Nayak AR, Chaudhury D, Reddy JN. Genetic divergence in scented rice. Oryza. 2004; 41:79-82

14. Tripathi P, Tripathi RD, Singh RP, Dwivedi S, Goutam $\mathrm{D}$, Shri M. et al. Silicon mediates arsenic tolerance in rice (Oryza sativa L.) through lowering of arsenic uptake and improved antioxidant defence system. Ecological engineering, 2013; 52:96-103.

15. Ward $\mathrm{Jr} \mathrm{JH}$. Hierarchical grouping to optimize an objective function. Journal of the American Statistical Association. 1963; 58(301):236-244. 